\title{
ROTE LEARNING: THE UGLY DUCKLING OF STUDENT PARAMEDIC EDUCATION?
}

\author{
David N. Long PhD ${ }^{1^{*}}$, Lisa Hobbs MPhil(c) ${ }^{1}$, Scott Devenish $\mathrm{PhD}^{1}$
}

*dn.long@qut.edu.au

\section{OPEN ACCESS ARTICLE}

Recommended Citation: Long D, Devenish A, Hobbs L. Rote learning: the ugly duckling of student paramedic education? Irish Journal of Paramedicine. 3(2). Sept 2018. https:// doi.org/10.32378/ijp.v3i2.97

Received: 24 Jul 2018

Accepted: 05 Sep 2018

Published: 26 Sep 2018

Copyright: @ 2018, the authors. This is an Open Access article distributed under the terms of the Creative Commons Attribution-Non-CommercialShare Alike 4.0 International licence which permits use, distribution, and reproduction in any medium, provided the original work and any attributes thereof are properly cited, are distributed under the same licence, and that the work is not used for commercial purposes.

\section{(c) (i) $($ )}

Funding/support: None declared.

Competing interests: None declared.

Provenance and review: Not commissioned, peer-reviewed.

\section{Author affiliations}

1. Queensland University of Technology, QLD, Australia

Acknowledgements:

Queensland University of Technology - School of Clinical Sciences

\section{Abstract}

\section{Introduction}

The intent of this commentary is to ask questions and stimulate discussion amongst academics and paramedic educators as to whether the inherent value of rote learning has simply been lost in the shadow of more recent learning and teaching practices.

Keywords: paramedicine, higher education, rote learning 
The vocational training of paramedics prior to the mid-1990s in Australia can possibly be characterised as draconian. Stories of preceptors wielding baseball bats in the middle of the night demanding that hapless paramedic students recite treatment protocols verbatim are hopefully apocryphal. Paramedics were required to learn protocols and pharmacology by rote under pressure with the pedagogical view that they could call on this information quickly in a life and death crisis. Thus, rote learning may have been associated with intimidation and trepidation. Nevertheless, the learning philosophy underpinning rote learning for the student paramedic, whereby the student completes a task repetitiously or memorises textual information, receives little attention in the education literature. With the advent of transformative changes in higher education towards the delivery of flexible, innovative and engaging learning experiences (1), rote learning barely raises a whisper. Has rote learning become the ugly duckling of student paramedic education?

The literary discourse surrounding rote learning is infused with negative undertones. Rote learning is often assumed as superficial learning $(2,3)$, and a transitional way-point towards critical thinking and meaningful learning (4). Arguably, paramedicine has adopted a similar learning trajectory to cognate disciplines. For instance, the seminal works of Benner guided by the Dreyfus model of skill acquisition (5) argue that the novice nursing student operates within a closed framework of rules and guidelines accentuated by rote learning. Borrowing from Aristole, Benner in later works argued that clinical practice is an amalgam of techné (standardisation of practice) and phronesis (situated actions based on skill, judgement, wisdom and character)(5). For example, while some clinical skills are relatively simple to execute, such as the taking of vital signs, good clinical judgement relies on deeper, experiential learning to interpret trends in the vital signs that may signal significant changes in a patient's condition. Similarly, learning ECGs may begin with memorising basic patterns of various rhythms from which the more complex skills of interpretation are built. It is generally accepted that the underpinning pedagogy of the higher education approach is better suited to paramedic education than the post-employment (vocational) model in developing students with critical appraisal, problem-solving and life-long learning skills (6). However, in our inexorable march towards professionalism, has the singular value of rote learning been lost to the annals of history?

Similar to nursing, paramedicine is a practical, skills-based profession requiring technical expertise in the day-to-day work of a paramedic. The scope of practice of a paramedic may include dozens of clinical procedures, some of which are relatively common, e.g., pulse oximetry and blood glucose analysis, whereas other critical procedures such as defibrillation are utilised infrequently (7). Developing automaticity through rote learning has notable advantages for student paramedics. Rote learning may ensure a solid grounding for the foundational skills of paramedic practice before the scaffolding of more complex higher reasoning skills are added. Additionally, while it is well accepted that clinical practice guidelines (CPGs) should not be applied mechanistically, rote learning may act as a clinical safety net because it provides an algorithm of clinical management in response to certain patient presentations, such as cardiac arrest. Memorisation of compression and ventilation rates, drug doses and defibrillator settings may improve skill reliability in stressful situations, particularly with infrequently used skills or when the clinician is fatigued.

Rote learning through repetition and memorisation needs not be seen as anathema to contemporary higher education pedagogies. Certainly, this commentary is not arguing for the reinstatement of rote learning as the primary learning tool for student paramedics. Rather, the intent is to ask questions and stimulate discussion amongst academics and paramedic educators as to whether the inherent value of rote learning has simply been lost in the shadow of more recent learning and teaching practices. Continuing the Hans Christian Andersen's ugly duckling analogy, perhaps it is time for rote learning to reemerge as a valued subsidiary of paramedic education.

\section{References}

1. Cathcart A, Greer D, Neale L. Learner-focused evaluation cycles: Facilitating learning using feedforward, concurrent and feedback evaluation. Assessment \& Evaluation in Higher Education. 2014;39(7):790-802. https:// doi.org/10.1080/02602938.2013.870969 
2. Johanns B, Dinkens A, Moore J. A systematic review comparing open-book and closed-book examinations: Evaluating effects on development of critical thinking skills. Nurse Education in Practice. 2017;27:89-94. https://doi.org/10.1016/ j.nepr.2017.08.018

3. Clayton L. Concept mapping: an effective, active teaching-learning method. Nursing Education Perspectives. 2006;27(4):197-203.

4. Malatji K. Moving away from rote learning in the university classroom: The use of cooperative learning to maximise students' critical thinking in a rural university of South Africa. Journal of Communication. 2016;7(1):34-42. Available from: http://krepublishers.com/02-Journals/JC/JC-07-0-000-16-Web/JC-07-1-000-16Abst-PDF/JC-07-1-SV-032-16-186-Malatji/JC-07-1-SV-032-16-186-Malatji-Tx\% 5B4\%5D.pdf

5. Benner P. Using the Dreyfus Model of Skill Acquisition to Describe and Interpret Skill Acquisition and Clinical Judgment in Nursing Practice and Education. Bulletin of Science, Technology \& Society. 2004;24(3):188-99. Available from: http://www.nurse.cmu.ac.th/web/images/userfiles/files/Handout-03.pdf

6. O’Brien K, Moore A, Hartley P, Dawson D. Lessons about work readiness from final year paramedic students in an Australian university. Australasian Journal of Paramedicine. 2013;10(4). Available from: https://ajp.paramedics.org/index.php/ ajp/article/view/52/44

7. Carlson J, Karns C, Mann C, Jacobson K, Dai M, Colleran C, et al. Procedures Performed by Emergency Medical Services in the United States. Prehospital Emergency Care. 2016;20(1):15-21. https:// doi.org/10.3109/10903127.2015.1051682 